3 Gluckman PD, Wyatt JS, Azzopardi D, et al. Selective head cooling with mild systemic hypothermia after neonatal encephalopathy: multicentre randomised trial. Lancet 2005;365:663-70.

4 Shankaran S, Laptook AR, Ehrenkranz RA, et al. Whole-body hypothermia for neonates with hypoxic-ischemic encephalopathy. N Engl J Med 2005;353:1574-84.

\section{Re: Palliation bias is being overlooked in neonatal hypothermia trials}

We thank Ziinu for the comments on our review. We agree that there is a risk of bias when the intervention is unmasked and this may also influence the decision to withdraw intensive care. Indeed, this is one reason why studies have chosen a composite outcome measure that includes rates of disability, but we agree that this does not completely remove the possibility of bias. It is one reason why we advise caution in the interpretation of the reported results and why a metaanalysis of the current studies can only be speculative. The additional data from approximately 600 infants that are being recruited in ongoing studies will help determine the efficacy of therapeutic hypothermia more precisely. We need to await those results before therapeutic hypothermia is considered standard treatment for perinatal asphyxia.

A D Edwards, D V Azzopardi

Department of Paediatrics, Imperial College London London, UK

Correspondence to: A D Edwards, Department of Paediatrics, Hammersmith Hospital, Du Cane Road London W12 ONN, UK

david edwards@imperial.ac.uk

Competing interests: None declared.

\section{Reference}

1 Ziino AJA. Palliation bias is being overlooked in neonatal hypothermia trials. Arch Dis Child. Published Online First: 27 Feb 2006 doi:10.1136/adc.2006.097394.

\section{Falling rates of perinatal postmortem examination: are we to blame?}

Information from a high-quality postmortem examination is the right of every parent after the death of their child. ${ }^{1}$ Postmortem examination rates worldwide, however, continue to fall. Much of this decline has been attributed to changing societal views on postmortem examination, recent issues of organ retention, and evidence to suggest that parents or carers are less likely to give consent. $^{2}$

Having reviewed our own practice, we hypothesised that rather than a decline in parental consent, clinicians were less likely to offer a postmortem examination. In November 2004, we carried out a semistructured telephone interview of 60 consultants from 46 level 2 and level 3 neonatal units in England and Wales. There were three interviewers, and the interview took between 5 and $10 \mathrm{~min}$ to complete. Given the several clinical scenarios, ranging from an infant born at 23 weeks' gestation who could not be resuscitated at birth to a term infant with seizures and evidence of grade-III hypoxic-ischaemic encephalopathy, we asked
Table 1 Reasons for not offering a postmortem examination to all bereaved parents

\begin{tabular}{ll} 
Reason & $\begin{array}{l}\text { Respondents } \\
(\%)\end{array}$ \\
\hline $\begin{array}{l}\text { Concern that the result might } \\
\text { question your clinical judgement }\end{array}$ & 2 \\
Being uncomfortable with the \\
postmortem examination process \\
yourself
\end{tabular}

consultants in what circumstances they would offer parents a postmortem examination. We found that $60 \%$ of consultant neonatologists interviewed would routinely offer a postmortem examination in the event of every neonatal death.

Of the $40 \%$ who did not routinely offer a postmortem examination, more than half had a clear reason for why they did no (table 1). In all, 35\% of consultants were not offering bereaved parents a postmortem examination owing to lack of availability of a perinatal pathologist; $37 \%$ of respondents thought that the perinatal postmortem examination seldom provided useful new information about a case (ie, in $<25 \%$ of cases); $66 \%$ of consultants believed that with the new consent process, their discussions with parents were now more difficult because of the explicit nature of information shared from a postmortem examination; and $80 \%$ of consultants had received no formal training in obtaining consent for a postmortem examination.

Offering a postmortem examination and asking parents for consent after the death of their child is one of the most emotive and challenging areas in which neonatologists work. McHaffie et $a l^{4}$ in their study on parents, 3 and 13 months after the death of their child, showed that the biggest parental reasons for refusing consent to postmortem examination were the dread of the child being mutilated and a feeling that there were no unanswered questions. The perinatal postmortem examination, however, remains the gold standard for investigating perinatal death. With new information available in as many as $40 \%$ of perinatal postmortem examination, ${ }^{3}$ we owe it to the parents of babies who have died and to future infants in our care to be sure that we have the best explanation of why a child died. Our study suggests that $40 \%$ of consultants are not offering parents this opportunity. The lack of availability of a perinatal pathologist remains the biggest single reason why clinicians are not offering postmortem examination to all bereaved parents.

\section{Acknowledgements}

We thank consultants from neonatal intensive care units around England and Wales for their participation in this study.
M Evans

NHS Lothian-University Hospitals Division Edinburgh, UK

J Tooley

Peter Dunn Intensive Care Unit, St Michael's Hospital

Correspondence to: I Tooley, Peter Dunn Intensive Care Unit, St Michael's Hospital, Southwell Street, Bristol BS2 8EG, UK. james.tooley@bris.ac.uk

doi: 10.1136/adc. 2005.091314

Competing interests: None.

\section{References}

1 Royal College of Paediatrics and Child Health The future of paediatric pathology services. London: RCPCH, 2002

2 Khong TY, Mansor FAW, Staples AJ. Are perinatal autopsy rates satisfactory? Med J Aust 1995; 162:469-70.

3 Saller DN Jr, Lesser KB, Harrel U, et al. The clinical utility of the perinatal autopsy. JAMA 1995;273:663-5.

4 McHaffie HE, Fowlie PW, Hume R, et al. Consent to autopsy for neonates. Arch Dis Child Fetal Neonatal Ed 2001;85:F4-7.

\section{Delay in screening premature infants for congenital hypothyroidism}

Optimal management of congenital hypothyroidism (CHT) includes early diagnosis and prompt treatment. ${ }^{1-3}$ We conducted an audit over a 12-week period in 2002 to determine whether time of screening for CHT was in adherence to standards published by the UK Newborn Screening Programme. The minimum standards recommended for time of screening for CHT is 5-8 days of life. ${ }^{4}$

Screening for CHT was carried out at the Regional Screening Laboratory, Royal Liverpool Children's Hospital, Alder Hey, Liverpool, UK. During the study period, 6425 infants with complete data were included for analysis. In premature infants $(\mathrm{n}=591)$, median age of CHT screening was 10 days compared with 7.6 days in term infants $(n=5834)$. In all, $25 \%$ of premature infants were screened at age $\geqslant 10$ days compared with $8 \%$ of term infants $(\mathrm{p}<0.001)$. Age of screening was significantly delayed in premature infants and the more premature infants seemed to have a greater time delay for screening $(\mathrm{r}=-0.3, \mathrm{p}<0.001)$.

The audit showed that premature infants are at risk of delayed screening for thyroidstimulating hormone, which may have a marked effect on the neurodevelopmental outcome. ${ }^{2}{ }^{3}$ This may be due to interhospital transfers, lack of prioritisation of the Guthrie test during management of sick premature infants or an intentional delay in obtaining blood spots to simultaneously obtain phenylalanine levels, which requires the infants to be fully enteral fed. Medical staff need to be educated on the importance of obtaining routine screening blood samples for CHT between day 5 and 8 of life in premature infants in accordance with standards recommended, regardless of clinical condition.

S M Ng, S C Wong, F Paize, E Chakkarapani Endocrinology Department, Royal Liverpool Children's Hospital Alder Hey, Liverpool, UK

P Newland, D M Isherwood Biochemistry Department, Royal Liverpool Children's Hospital Alder Hey 
M Didi

Endocrinology Department, Royal Liverpool Children's Hospital Alder Hey

Correspondence to: $\operatorname{Dr} S \mathrm{M} \mathrm{Ng}$, Endocrinology Department, Royal Liverpool Children's Hospita Alder Hey, Eaton Road, Liverpool L12 2AP, UK; ngszemay@yahoo.com

doi: 10.1136/adc.2005.091264

Competing interests: None declared.

\section{Reference}

1 Law WY, Bradley DM, Lazarus JH, et al. Congenital hypothyroidism in Wales (19821993): demographic features, clinical presentation and effects on early neurodevelopment. Clin Endocrinol (Oxford) 1998:48:201-7.

2 Meijer WJ, Verloove-Vanhorick SP, Brand R, et al. Transient hypothyroxinemia associated with developmental delay in preterm infants. Arch Dis Child 1992:39:142-5

3 Lucas A, Rennie J, Baker BA, et al. Low triiodothyronine concentrations in preterm infants and subsequent intelligence quotient at 8 year follow up. BMJ 1996:312:1132-3.

4 UK Newborn Screening Programme Centre. Newborn blood spot screening in the UK: policie and standards. London: Department of Health, 2005, http://www.newbornscreeningbloodspot.org.uk (accessed 23 Aug 2006).

\section{Neonatal resuscitation in Italy: an ethical perspective}

The attitudes of doctors and nurses toward neonatal resuscitation have been described previously. ${ }^{1}$ However, the studies were conducted before the publication of the last versions of the official international guidelines for neonatal resuscitation, in which, for the first time, some practical indications related to the ethical aspects were reported. ${ }^{2}{ }^{3}$

We aimed to survey the practice and the approach to neonatal resuscitation in Italian tertiary centres from an ethical perspective.

A structured 73-item questionnaire and an accompanying introductory letter was sent by email to the heads of the 86 tertiary centres provided with on-site delivery. ${ }^{3}$ The questions included multiple-choice, fill-in and yes /no questions.

Information was obtained from $76(88.3 \%)$ centres. In all, $38(50 \%)$ units had a written protocol for deciding the management of the ELBWI in the delivery setting and $45(59.2 \%)$ centres declared referring to a specific gestational age (mean $\geqslant 23$, range $22-24$ weeks) or birth weight (mean $\geqslant 400$, range $350-500 \mathrm{~g}$ ) for initiating full intensive care. In 2002 at the surveyed centres, the lowest mean gestational age and birth weight at which an ELBWI received full resuscitation were 23 (range 2027) weeks and $480(300-750)$ g, respectively.

Figures 1 and 2 show the choices of the head doctors (and their colleagues) when faced with the birth of an extremely premature infant. In these situations, the final therapeutic decision is routinely taken by the attending doctor $(47.9 \%)$ or by the obstetricneonatal team $(52.1 \%)$. The head doctors of the Italian III level centres consider that in their centre, the feeling among the doctors facing the birth of an extremely premature infant is considered: low (11.1\%), sufficient $(32 \%)$, good $(54.1 \%)$ and very good $(2.8 \%)$. Hospital ethics committees at $21(27.6 \%)$ centres play a part in decision making for individual cases.

When confronted with a full-term infant with cardiorespiratory arrest (Apgar score 0),

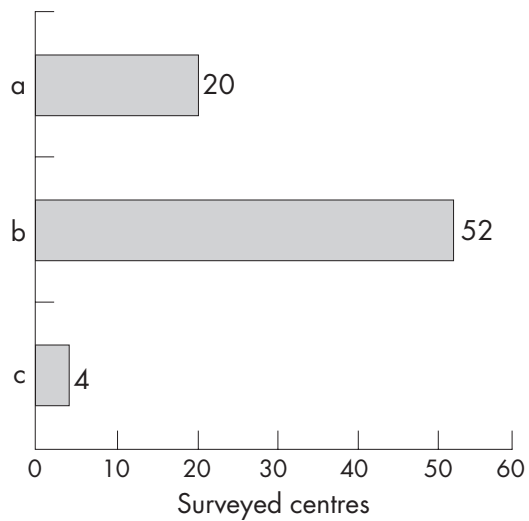

Figure 1 Decision-making in the delivery room. A woman starts labour at 23 complete weeks of pregnancy. No fetal distress is detected and the baby's weight is estimated as $500 \mathrm{~g}$. At birth, Apgar score at 1 minute is 1. Would you: (a) resuscitate the baby and start intensive care even if you knew that, once started, intensive care would not be withdrawn whatever the prognosis; (b) resuscitate the baby and start intensive care, provided that intensive care can later be withdrawn if the baby's prognosis appears poor; or (c) withhold resuscitation.

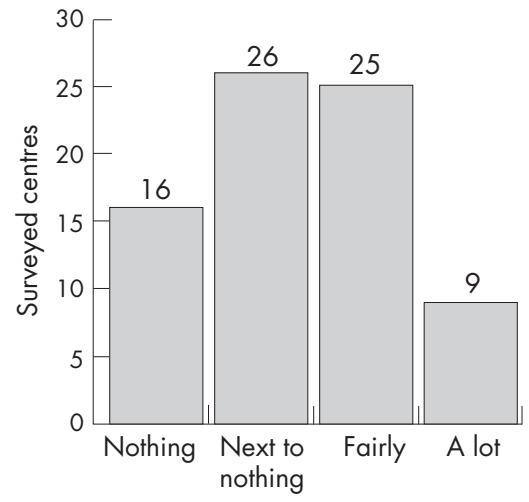

Figure 2 Decision-making in the delivery room (see fig 1). In this case, the parents wishes would influence the therapeutic choice

discontinuation of resuscitative efforts is made after 10, 15 and $20 \mathrm{~min}$ at 16 $(21.0 \%), 18(23.6 \%)$ and $18(23.6 \%)$ centres, respectively. A specific time for discontinuation of resuscitative efforts in case of severe asphyxia is not codified at $24(31.8 \%)$ centres.

When confronted with the birth of a neonate with confirmed trisomy 13, 30 $(39.4 \%)$ centres would start resuscitation and intensive care and 46 (60.5\%) would give palliative care.

Although international guidelines were designed to standardise and optimise resuscitation in newborns, ${ }^{23}$ previous studies showed that deviations are frequent. ${ }^{4}$ From an ethical perspective, our data show that the adherence to neonatal resuscitation guidelines is low across Italian tertiary centres. When evaluating the approach to neonatal resuscitation, other factors, along with professional guidelines, have to be considered.

D Trevisanuto, N Doglioni

Paediatric Department, School of Medicine, University of Padova, Padova, Italy
M Micaglio

Department of Pharmacology and Anaesthesiology, School of Medicine, University of Padova

R Bortolus

International Centre on Birth Defects, Rome, Italy

V Zanardo

Paediatric Department, School of Medicine, University of Padova, Padova

Correspondence to: D Trevisanuto, Paediatric Department, University of Padova, Via Giustiniani 3 , 35128 Padova, Italy trevo@pediatria.unipd.it

doi: 10.1136/adc.2005.092627

Competing interests: None.

\section{References}

1 De Leeuw R, Cuttini $M$, Nadai $M$, et al. Treatment choices for extremely preterm infants: an international perspective. J Pediatr 2000;137:608-15.

2 Niermeyer S, Kattwinkel J, Van Reempts P, et al. International guidelines for neonatal resuscitation: an excerpt from the guidelines 2000 for cardiopulmonary resuscitation and emergency cardiovascular care. International consensus on science contributors and reviewers for the neonatal resuscitation guidelines. Pediatrics 2000; 106:e29.

3 Anon. Neonatal resuscitation guidelines. Circulation 2005;112:IV-188-195.

4 Trevisanuto D, Doglioni N, Ferrarese $P$, et al. Neonatal resuscitation of extremely low birth weight infants: a survey of practice in Italy. Arch Dis Child Fetal Neonatal Ed 2006;91:F123-4.

\section{Presence of parents during ward rounds: experience from a Greek NICU}

We read with interest the paper by Bramwell et al $^{1}$ and we would like to add our experience on this issue. An unrestricted visiting policy has been practised at our neonatal intensive care unit (NICU) since the early 1980s. Even now, this is the only unit practising unrestricted visiting among the 15 NICUs in Greece. Initially, parents were present during ward rounds. However, several things became apparent:

1. During ward rounds, parents present were trying to overhear what was discussed about their baby. It was also evident that they could neither understand the medical jargon that was used nor fully appreciate what had been discussed. This had often led to misunderstandings regarding their baby's true condition. These erroneous perceptions had to be corrected and explanations given by the medical staff. Also, parents seemed to fixate on numbers of laboratory results mentioned during the ward round, which again had led to erroneous perceptions regarding their baby's true condition.

2. Parents who had overheard medical discussions regarding other babies had sometimes contacted and informed the parents of the relevant baby. This on some occasions had created problems, with the particular parents receiving information in such a manner, and further explanations had to be given by the medical staff. Also, some parents complained that they did not wish other parents to overhear information regarding their baby.

3. Medical and nursing staff believed that the presence of parents had a restrictive effect on how the baby's condition could or should be discussed. 